\title{
Timing of transjugular intrahepatic portosystemic stent-shunt in Budd-Chiari syndrome: A UK hepatologist's perspective
}

\author{
Faisal Khan $^{1}$, Homoyon Mehrzad ${ }^{2}$, Dhiraj Tripathi ${ }^{1}$ \\ 'Liver Unit, Queen Elizabeth Hospital Birmingham, UK; \\ ${ }^{2}$ Imaging and Interventional Radiology Department, Queen Elizabeth Hospital Birmingham, UK.
}

\section{ABSTRACT}

Budd-Chiari syndrome (BCS) is a rare but fatal disease caused by the obstruction in hepatic venous outflow tract (usually by thrombosis) and is further classified into two subtypes depending on the level of obstruction. Patients with BCS often have a combination of prothrombotic risk factors. Clinical presentation is diverse. Stepwise management strategy has been suggested with excellent 5 -year survival rate. It includes anticoagulation, treatment of identified prothrombotic risk factor, percutaneous recanalization, and transjugular intrahepatic portosystemic shunt (TIPS) to reestablish hepatic venous outflow and liver transplantation in unresponsive patients. Owing to the rarity of BCS, there are no randomized controlled trials (RCTs) precisely identifying the timing for TIPS. TIPS should be considered in patients with refractory ascites, variceal bleed, and fulminant liver failure. Liver replacement is indicated in patients with progressive liver failure and in those in whom TIPS is not technically possible. The long-term outcome is usually influenced by the underlying hematologic condition and the development of hepatocellular carcinoma. This review focuses on the timing and the long-term efficacy of TIPS in patients with BCS.

Key words: Budd-Chiari syndrome, percutaneous recanalization, transjugular intrahepatic portosystemic shunt (TIPS), liver transplantation.

\section{BACKGROUND}

Budd-Chiari syndrome (BCS) is a rare and life-threatening vascular disorder, consisting of hepatic venous outflow obstruction at any level between the small hepatic veins and the right atrium. ${ }^{[1,2]}$

BCS is classified into two categories. BCS is regarded as secondary BCS when the hepatic flow is obstructed by compression or invasion of a lesion outside the hepatic venous outflow track (benign or malignant tumors, cysts, abscess, and so on). ${ }^{[3]}$ BCS is regarded as primary BCS if the flow is obstructed because of the primary venous anomaly, usually thrombosis. ${ }^{[3]}$

Primary BCS is further classified in two types according to the anatomical location of the venous obstruction: A "classical BCS" type in which the obstruction occurs within the hepatic vein and "hepatic venacava BCS," which involves thrombosis of the intra/suprahepatic portion of the IVC. ${ }^{[4]}$ The former has potentially more severe outcome than the latter, which has a more chronic evolution and milder symptoms.

\section{EPIDEMIOLOGY}

Estimated incidence of BCS in the West is 1 in 2.5 million per person-year, ${ }^{[5]}$ and this is fairly consistent across Europe. However, there are significant geographic differences among Asian countries. ${ }^{[6]}$ In the Western world, classical BCS is the most common form of primary BCS, whereas the most frequent cause of hepatic vein occlusion is thrombosis due to thrombophilic disorders. On the contrary, in Asian population, hepatic vena cava BCS is the most common form of the primary BCS and is mostly idiopathic or related to anatomical anomalies such as membranous obstruction. ${ }^{[7}$ 


\section{ETIOLOGY AND PATHOGENESIS}

Irrespective of the cause, in hepatic venous outflow obstruction, hepatic sinusoidal pressure increases and portal hypertension develops quickly, resulting in venous congestion and ischemic necrosis to the surrounding sinusoidal hepatocytes. ${ }^{[8]}$ If hepatic sinusoidal pressure is not relieved by therapeutic interventions or the development of a venous collateral system, then nodular regeneration, fibrosis, and ultimately cirrhosis occur. ${ }^{\left[{ }^{[0]}\right.}$

Primary BCS is considered a multifactorial disease, which can involve a combination of prothrombotic conditions. ${ }^{[5,10-12]}$ The discovery of one causal factor should not discourage further investigation to identify other prothrombotic conditions. These prothrombotic conditions include myeloproliferative diseases, Factor V Leiden mutation, prothrombin gene mutation, protein $\mathrm{C}$ deficiency, protein $\mathrm{S}$ deficiency, antithrombin deficiency, antiphospholipid syndrome, hyperhomocysteinemia, and paroxysmal nocturnal hemoglobinuria. BCS is also associated with systemic inflammatory diseases, such as inflammatory bowel disease, sarcoidosis, and Behçet's disease. ${ }^{[13]}$

\section{CLINICAL PRESENTATION AND DIAGNOSIS}

The clinical presentation of BCS is heterogeneous ${ }^{[1]}$ and BCS can be classified as acute, sub-acute, or chronic. ${ }^{[6]}$ Rarely, it causes acute liver failure. ${ }^{[14]}$ Most of the patients present with abdominal pain, ascites, and hepatomegaly. Less common clinical manifestations include esophageal bleeding and hepatic encephalopathy. ${ }^{[8]}$ About $15 \%$ of patients are asymptomatic. ${ }^{[15]}$
The diagnosis of BCS is based on the demonstration of a hepatic venous outflow tract obstruction on imaging such as Doppler ultrasonography, ${ }^{[16]}$ computed tomography (CT), or magnetic resonance imaging (MRI). A liver biopsy may play a role if there is uncertainty about the diagnosis and usually shows evidence of sinusoidal congestion and sometimes perisinusoidal fibrosis as a result of outflow obstruction. Liver biopsy is essential if small vessel BCS is suspected. ${ }^{[17]}$ Once diagnosis of BCS is made, a thorough workup should be undertaken to identify the multiple underlying prothrombotic risk factors.

\section{THERAPIES}

Without treatment, BCS is a life-threatening condition, with high mortality rate. ${ }^{[2,18]}$ Over the past decade, treatment of BCS has been progressively standardized ${ }^{[2,18,19]}$ based on a stepwise approach to control clinical manifestations (such as ascites or variceal bleeding), to prevent the extension of venous thrombosis, to reestablish venous drainage of the liver, and for the prompt identification and treatment of underlying diseases. ${ }^{[1,20]}$ Long-term anticoagulation therapy should be promptly initiated in all patients with BCS in the absence of contraindications. In patients with persistent symptoms, endovascular procedures that include thrombolysis and/or combined with mechanical thrombectomy, percutaneous transluminal angioplasty, or stent placement are performed to restore hepatic blood flow in patients with segmental HV or IVC obstruction. Transjugular intrahepatic portosystemic shunt (TIPS) or direct intrahepatic portocaval shunts (DIPS) should be used if angioplasty/stenting is not technically feasible or severe portal hypertension complications or persistently deteriorated liver function develops (Figure 1). Liver

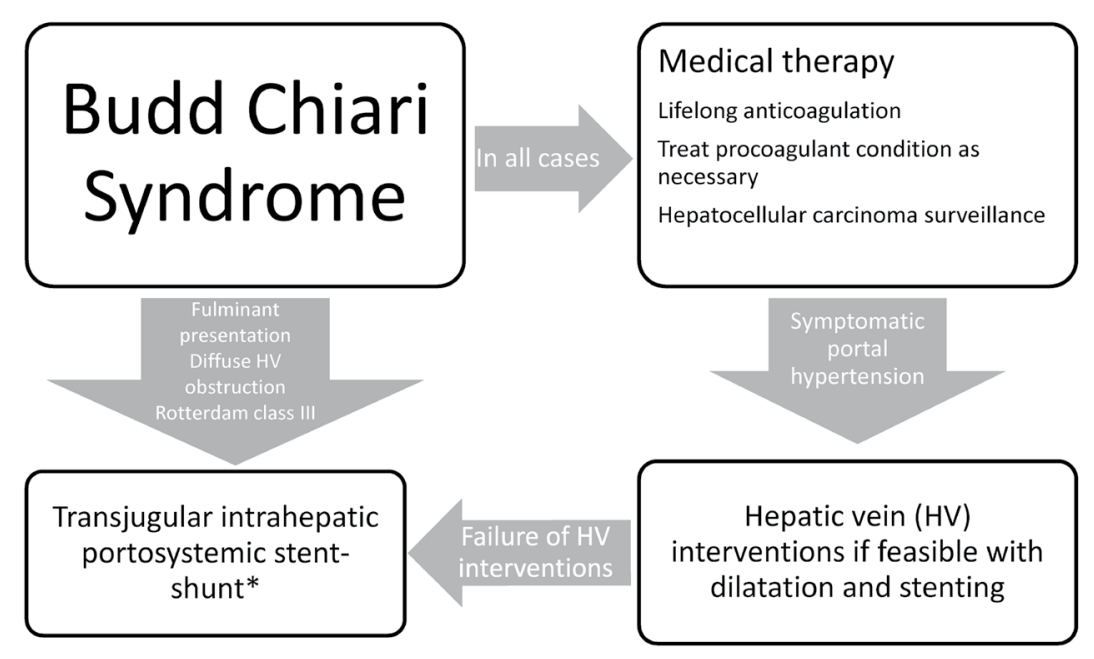

Figure 1: Stepwise management of BCS. *Consider referral for early liver transplant in suitable candidates if the BCS-TIPS score is $>7$. BCS, Budd-Chiari syndrome; TIPS, transjugular intrahepatic portosystemic shunt. 
transplantation is the final therapeutic option in severe BCS unresponsive to hepatic venous interventions or TIPS. Liver transplantation can also be considered as first-line therapy in patients who present with fulminant liver failure.

\section{Medical treatment}

Patients with BCS would require anticoagulant therapy for an indefinite period of time, even after radiological or surgical interventions. ${ }^{[1,20]}$ Anticoagulation alone is sufficient in controlling the mild form of liver disease in about $15 \%$ of patients. ${ }^{[1,21]} \mathrm{LMWH}$ is the preferred initial anticoagulant followed by vitamin $\mathrm{K}$ antagonists (target INR between 2 and 3). ${ }^{[9]}$ Ascites is managed with diuretics and low salt diet. Underlying prothrombotic conditions should be extensively looked for and be treated promptly.

Primarily data shows that new oral anticoagulants (NOACs) are effective and safe in patients with splanchnic venous thrombosis and cirrhosis; however, there are no data to support their usage in patients with BCS as yet. ${ }^{[22]}$

\section{Radiological therapies}

Vascular intervention in BCS aims to relieve hepatic congestion either through correction of obstruction or the creation of a bypass. The aim is to restore the hepatic blood flow to prevent hypoxia and hepatocyte necrosis caused by continued hepatic congestion.

\section{Percutaneous recanalization/Stenting}

About one-third of patients with BCS have shortlength stenosis of either the hepatic veins or IVC. These patients can be treated with recanalization by percutaneous angioplasty with or without stenting. The long-term efficacy and safety of hepatic vein interventions procedure have been shown in various studies. ${ }^{[23-25]}$ An important technical consideration to keep in mind before undertaking a hepatic vein stent is the quality of hepatic vein to be stented. This really means in terms of the size and potential flow into the hepatic vein. In our experience, if the salvageable vein is small, this usually can correlate with reduced/slow flow into the stent after the procedure and, hence, the risk of thrombosis of the vein. In these cases, it may be better to consider either TIPS or DIPS instead. It is important to obtain accurate imaging of the hepatic veins first through cross-sectional imaging and ultrasound and also consider either retrograde or percutaneous hepatic venography before deciding on the appropriate intervention. This is a crucial step in the process as avoiding an unnecessary procedure will potentially save time in terms of improving the venous congestion. Most of these cases are better performed under general anesthesia because of the comfort of the patient and the length of procedure.
Tripathi et al. published analysis of 63 patients with BCS who underwent venoplasty at their center and compared this to a previously reported series of patients treated by TIPS $(n=59) .{ }^{[25]} \mathrm{A}$ total of 32 patients were treated with $\mathrm{HV}$ venoplasty alone, and 31 had endovascular stents placement. Over the median follow-up of 113 months, technical success achieved was $100 \%$, with symptom resolution in $73 \%$. The cumulative secondary patency at 1,5 , and 10 years was $92 \%, 79 \%$, and $79 \%$, respectively, in the stenting group and $69 \%, 69 \%$, and $64 \%$, respectively, in the venoplasty group. A total of 10 patients required TIPS, and 8 underwent surgery when long-term patency was not achieved. The actuarial survival rate at 1,5 , and 10 years was $97 \%, 89 \%$ and $85 \%$, respectively. When compared to TIPS, HV interventions resulted in similar patency and survival rates but with significantly lower procedural complications $(9.5 \%$ vs. $27.1 \%)$ and hepatic encephalopathy $(0 \% v$ s. $18 \%)$. The authors supported the stepwise approach for the management of BCS, with very good outcomes from venoplasty combined with stenting when required. They concluded that TIPS should only be offered in conditions in which HV interventions are not feasible or unsuccessful.

Angioplasty has been extensively used in Asia. ${ }^{26-31]}$ Han et al. published their experience with a median followup of 30 months in 167 patients referred for percutaneous angioplasty. ${ }^{[31]}$ Technical success was $86 \%$ for hepatic vein obstruction alone, and more than $96 \%$ for IVC with or without hepatic veins. The 5 -year cumulative primary and secondary patency rates were approximately $80 \%$ and $90 \%$, respectively. Cumulative survival rate in patients with successful recanalization was $80 \%$ at 5 years.

\section{Transjugular Intrahepatic portosystemic shunt}

For more than two decades, TIPS has been successfully used for the management of complications of portal hypertension. ${ }^{[32]}$ TIPS (with bare stents) were first used for the treatment of BCS in the early 1990s, ${ }^{[3,34]}$ and it has been shown to be an effective treatment of BCS in subsequent studies. ${ }^{[35-37]}$ Increasing number of patients with BCS have undergone TIPS, and it seems to be most frequent treatment for $\mathrm{BCS}^{[3,38,39]}$ in the Western population, and liver transplantation is only considered when endovascular procedures fail or symptoms persist. ${ }^{[18-19]}$ Over the past decade, polytetrafluoroethylene (PTFE) covered stents have been used, which resulted in increased patency rates. ${ }^{[5,40-43]}$

Given the rarity of BCS, there are no randomized controlled trials (RCT) precisely identifying the timing and candidates for TIPS in BCS. The two common indications established for patients with cirrhosis with portal hypertension (refractory ascites and recurrent variceal bleeding) are 
common indications for TIPS in patients with BCS as well. Diffuse thrombosis of HVs is another indication for TIPS, as with percutaneous angioplasty with or without stent placement, it is technically difficult to maintain the longterm HV patency in such patients. As mentioned previously, the suitability and patency of the hepatic vein stent largely depends on the size and quality of the remaining hepatic vein. TIPS should also be promptly performed in patients with progressive liver failure if medical therapy and/or percutaneous recanalization cannot fully control the disease progression. ${ }^{[39]}$ TIPS can be performed if it is technically possible to get access into the hepatic vein or at the level of the hepatic vein confluence, in order to then gain access into the portal vein. If this is not possible, then the operator can consider DIPS from the IVC through the caudate lobe and into the portal vein. This is usually assisted by the use of percutaneous ultrasound or intravascular ultrasound (IVUS) to help direct the puncture into the portal vein.

Various studies have shown good long-term outcome of TIPS placement in patients with BCS, with a high rate of technical success, secondary stent patency, and fairly low mortality. ${ }^{[22-50]}$

In a systemic review of published literature on TIPS in patients with BCS, Qi et al. reported high TIPS success rate, ranging from $91 \%$ to $100 \%{ }^{[51]}$ Short- and long-term prognoses of BCS-TIPS patients has been excellent with 1-year cumulative survival rate of $80-100 \%$ and 5 -year cumulative survival rate of $74-78 \%$ in various studies. ${ }^{[51]}$ The rate of TIPS-related complications was variable, ranging from $0 \%$ to $56 \%$ in various studies. These complications mainly included liver capsule perforation, IVC, and portal vein injury; contrast materials induced acute renal failure, and stent migration. TIPS-related deaths were rare. ${ }^{[51]}$ Shunt dysfunction appears to be more frequent in BCS-TIPS patients because of their prothrombotic states (range, $18-100 \%$ in 14 case series). This was more common in patients receiving bare stents than in patients receiving PTFE-covered stents. ${ }^{[51]}$ Hepatic encephalopatby was previously considered uncommon after TIPS, but the recent long-term data suggest that nearly $20 \%$ of BCSTIPS patient are affected. ${ }^{[25]}$

In another systematic review with meta-analysis of 2,255 patients with BCS that assesses the outcomes of interventional treatment for BCS, the technical success rate of TIPS insertion was $96.4 \%$. The survival rates in that meta-analysis at 1 and 5 years in TIPS group were $87.3 \%(95 \% \mathrm{CI}=83.2-91.3 \%)$ and $72.1 \%(95 \% \mathrm{CI}=$ $67.2-77.0 \%$ ), respectively. The patients with recanalization therapy had a better prognosis than with TIPS therapy in that study, but the physical conditions of patients with BCS in recanalization group are usually better than those in the
TIPS group. Therefore, the authors recommended stepwise management of BCS. ${ }^{\left[{ }^{26]}\right.}$ Both these meta-analysis reviews did not discuss the optimal timing of TIPS.

Garcia-Pagan et al. published their study of 124 patients with BCS who had TIPS for non-response to medical treatment or recanalization. Patients receiving TIPS had severe liver disease reflected by a high Child-Pugh score, MELD score, Clichy score, and Rotterdam score (RS). ${ }^{[42]}$ However, only 12 of $124(9.7 \%)$ patients were on oral anticoagulation up until TIPS. Timing of the TIPS has not been mentioned in the publication, but major indications of TIPS were refractory ascites (59\%), liver failure $(22 \%)$, and upper gastrointestinal bleeding $(9 \%)$. The 1-, 5-, and 10-year orthotopic liver transplantation (OLT)-free survival rates were $88 \%, 78 \%$, and $69 \%$, respectively. The authors developed a new prognostic score, the BCS-TIPS PI, to predict the outcome after TIPS, and it emerged as the most accurate clinical score at predicting 1-year survival rate in these patients. BCS-PI of $>7$ is associated with worse outcome and patients should be considered for early transplantation. The authors reported excellent long-term outcome for patients with severe BCS treated with TIPS during median overall follow-up of 36.7 months.

Seijo et al. conducted a multicenter prospective study in 157 patients from 9 European countries. ${ }^{[19]}$ Patients were followed for a median of 50 months (range, 0.174.0). More than $88 \%$ of patients received long-term anticoagulation. Sixty-nine patients (44\%) did not receive any intervention and nearly $30 \%$ of these patients died within the follow-up period. Twenty-two patients received angioplasty/thrombolysis. However, 14 (64\%) of them showed poor response and needed further treatment with either TIPS (12 patients) or OLT ( 2 patients), after a median time of 1.5 months (range, 0.2-19.0). Sixty-two (39.5\%) patients underwent TIPS as a rescue therapy after failure of medical or minimally invasive treatments. About half of the TIPS were placed in the first month and $60 \%$ in the first 3 months after diagnosis (median time from diagnosis to TIPS was 1 month (range, $0-38$ ). In this study, patients who underwent TIPS in the first month had more severe liver disease at diagnosis as well, which was reflected by worse Rotterdam PI score. Only 4 of these BCS-TIPS patients $(6.45 \%)$ needed rescue OLT at a median of 1.8 months after TIPS (range, 0.03-13.0). The 1-, 3-, and 5-year actuarial survival rates of BCS-TIPS patients were $88 \%$, $83 \%$, and $72 \%$, respectively, and the 1-, 3-, and 5-year OLTfree survival rates were $85 \%, 78 \%$, and $72 \%$, respectively. Twenty patients $(12.7 \%)$ in this study received OLT and $60 \%$ of OLT were performed in the first 6 months after diagnosis. Fifteen patients who had early OLT had severe liver disease (indicated by frequent hepatic encephalopathy, higher RS, and class) at diagnosis than the patients who 
received TIPS. Although most TIPS were placed during the first year after diagnosis, in this study, the timing of placement was not uniform and ranged from 0 to 38 months. Regardless of the timing of TIPS, the long-term outcome after TIPS was good. The authors claimed that the approach of close clinical surveillance while reserving TIPS for those patients who progress or fail to respond to medical treatment did not have a deleterious effect on outcome. However, nearly $30 \%$ of patients who did not have any intervention died during the follow-up period (probably because of progression of disease). Importantly, in this study, RS appeared to be an excellent prognostic value for predicting the need of invasive intervention and should be used early in deciding about the type of intervention, that is, TIPS for higher RS. In patients with BCS with TIPS, BCS-TIPS PI score appeared to be superior to RS for predicting survival and could be used for consideration of early OLT. However, the outcome of an early OLT in patients with a high BCS-TIPS PI score needs to be proved in clinical practice. A controlled trial may not be possible because of scarcity of this disease.

Contrary to wide use of TIPS in the treatment of patients with BCS in the Western countries; percutaneous recanalization is widely applied in most of the Chinese patients with BCS. ${ }^{[1,52-56]}$ This difference in choice of treatment modalities between Western countries and China is primarily because of the disparity in the type of obstruction and the risk factors of BCS. ${ }^{[7,57,58]}$ As stated earlier, the majority of western patients with BCS have obstruction of hepatic vein alone; ${ }^{[3,59]}$ whereas majority of Chinese patients with BCS have combined HV and IVC obstruction. ${ }^{[3,31,54,55]}$ In many of the Chinese studies, the long-term anticoagulation was not offered.

Tripathi et al. reported their experience in 67 patients with BCS (of 104 patients with BCS referred to single centre) who received TIPS between 1996 and 2012 with a mean follow-up period of 82 months (range, $0.5-184$ months). ${ }^{[43]}$ A total of 56 patients had TIPS as their first intervention, whereas 9 had previous treatments with hepatic vein dilatation or stenting and 2 patients had shunt surgery that failed to decompress the hepatic outflow. In these patients, the time from initial intervention to TIPS ranged from 1 to 132 months. Of these, $15 \%$ of patients developed postTIPS encephalopathy and 2 patient received OLT. The 1-, 2 -, 5-, and 10-year survival rates were $92 \%, 87 \%, 80 \%$, and $72 \%$, respectively.

Qi et al. conducted a large retrospective study in 51 Chinese patients who underwent TIPS for BCS, and majority of these patients (36 patients) had combined HV/IVC occlusion. ${ }^{[49]}$ Importantly, 175 of 230 patients (76\%) with primary BCS presented during the enrolment period
(December 2004 and June 2012) underwent successful percutaneous recanalization alone. Thirty-nine $(76 \%)$ of these 51 patients had percutaneous recanalization before TIPS. Main indications of TIPS were diffuse obstruction of three HVs $(n=12)$, liver failure $(n=2)$, liver function deterioration $(n=8)$, refractory ascites $(n=10)$, and variceal bleeding $(n=19)$. In this study, 19 (of 51) patients had early TIPS (either no prior percutaneous recanalization or percutaneous recanalization was performed within 3 days before TIPS). Thirty-two patients had late or converted TIPS (TIPS was performed $>3$ days after percutaneous recanalization). A "wait-and-see" attitude was adopted after percutaneous recanalization in later group, ${ }^{[12]}$ and then TIPS was performed as a result of the poor response, (progressive liver failure, liver function deterioration, diffuse obstruction of three HVs, variceal bleeding, and refractory ascites). Compared with the early TIPS group, the converted TIPS group had a longer history of BCS and a higher proportion of patients with combined IVC/HV obstruction. The mean follow-up time was $732.57 \pm 74.71$ (40-2,085) days. The cumulative 1-, 2-, 3-, 4- and 5-year survival rates were $83.82 \%, 81.20 \%, 76.93 \%, 67.31 \%$, and $56.09 \%$, respectively. The cumulative survival rate was similar between the early TIPS and converted groups. The time interval of TIPS intervention was not discussed in the article. However, the authors reiterated that patients with diffuse hepatic venous occlusion should be considered for TIPS (because of technical unfeasibility of percutaneous recanalization) and their treatment strategy (in this study) was consistent with the stepwise strategy used in the Western countries (Seijo et al). The authors concluded that TIPS could achieve an excellent survival rate in Chinese patients in whom percutaneous recanalization is ineffective or inappropriate, and BCS-TIPS score could effectively predict these patients' survival.

Rathod et al. demonstrated the efficacy and safety of venous recanalization and TIPS for BCS in Indian patients in their retrospective study of 190 patients (17 pediatric) in 1 Indian centre. In this cohort of patients, hepatic venous obstruction was observed in 147 patients, IVC obstruction was observed in 40 patients, and concomitant HV/IVC obstruction was observed in only 3 patients. ${ }^{[29]}$ The radiological interventions included hepatic vein plasty/ stenting in 38 patients (with short-segment HV occlusion), collateral vein stenting in 3 patients, IVC plasty/stenting in 40 patients, both IVC and hepatic vein stenting in 3 patients, and TIPS in 106 patients. They reported response in 153 patients $(80.5 \%)$ and repeat procedures were required in 19 patients $(10.0 \%)$. The median follow-up duration in this study was 42 (12-88) months. One patient (out of 40) with IVC plasty needed TIPS 6 years after initial intervention and 2 patients in the HV plasty group needed TIPS for symptoms recurrence during the follow-up period (timing 
not discussed in the article). According to the authors, the proportion of patients who were amenable to and underwent angioplasty and stenting was $47.4 \%$ (similar to Chinese cohort), probably because of IVC involvement.

\section{Surgical therapies}

\section{Surgical portosystemic shunts}

Surgical portosystemic shunting failed to show significant survival benefit in patients with BCS. This modality is, therefore, no longer considered as a treatment option and is largely replaced by TIPS. ${ }^{[19]}$ This could also be attributed to high perioperative mortality, ${ }^{[60]}$ low late shunt patency, and technical difficulties. ${ }^{[61,62]}$

\section{Orthotopic Liver transplantation (OLT)}

About $10-20 \%$ of patients with BCS show progressive liver deterioration despite medical management, revascularization, and TIPS. OLT is the only remaining treatment option in these patients. Benefit of OLT on survival has been evaluated in a few large retrospective analyses and reported a 5 -year survival rate between $71 \%$ and $89 \% .^{[63-65]}$ The survival benefit of OLT is most pronounced in patients with BCS with worse baseline characteristics (reflected by high Rotterdam score). The survival rate and graft function after OLT in patients with BCS are similar ${ }^{[64]}$ or even superior ${ }^{[63]}$ to those transplanted for other indications.

\section{CONCLUSION}

Owing to the scarcity of BCS, studies comparing different timings of TIPS in patients with BCS are lacking. The stepwise approach (and indications of TIPS) in management of BCS is based on the expert opinion and consensus (Figure 1). It suggests the next management strategy when there is poor response to one intervention. However, the definition for response to therapy has not been stated and the proposal of such definition would need validation. Moreover, about $30 \%$ of patients who received only medical treatment died in the study performed by Seijo et al, a high rate considering the availability of further effective intervention.

Medical therapy should probably be indicated as the sole treatment only in patients without any sign of portal hypertension. Patients with any signs of portal hypertension should be offered decompressive procedures. Short-length stenoses have been successfully treated with angioplasty/ stenting with good medium-term outcome. Hence, angioplasty/stenting is a potentially valuable treatment of the BCS in patients with short-length stenosis, with low Rotterdam score (especially in Asian patients, in whom different pathogenic mechanisms of hepatic venous outflow obstruction are thought to cause HV stenosis).
However, early TIPS can be considered in these patients but with high Rotterdam class (Rotterdam class III).

TIPS has also proven to be an effective and a safe treatment for BCS with diffuse occlusion of hepatic veins. Severe jaundice (bilirubin $>3 \mathrm{mg} / \mathrm{dL}$ ) and pre-TIPS hepatic encephalopathy are not considered contraindications for TIPS in BCS. In fact, patients diagnosed with these features should undergo TIPS as soon as possible as these patients have high mortality without TIPS. ${ }^{[6]]}$

Liver replacement may be the treatment of choice in patients with cirrhosis and severe impairment of liver function as well as selected patients with hepatocellular carcinoma. Occasionally, the presentation of BCS is fulminant and patients develop acute liver failure. The outcome in these patients has been relatively poor. In these patients, anticoagulation should be initiated as soon as the diagnosis of BCS is made. Decompression of liver with TIPS should be pursued earlier while the underlying cause of BCS is being determined. This intervention would provide clinicians with a window during which time assessment for clinical improvement can be made while the decision to list/transplant is undertaken.

\section{Conflict of Interests}

Dr. Dhiraj Tripathi and Dr. Homoyon Mehrzad got speaker fees for Gore Medical.

\section{REFERENCES}

1. Garcia-Pagàn JC, Buscarini E, Janssen HL, Leebeck FW, Plessier A, Rubbia-Brandt L, et al; European Association for the Study of the Liver. EASL Clinical Practice Guidelines: Vascular diseases of the liver. J Hepatol 2016; 64: 179-202.

2. Janssen HL, Garcia-Pagan JC, Elias E, Mentha G, Hadengue A, Valla DC; European Group for the Study of Vascular Disorders of the Liver. Budd-Chiari syndrome: a review by an expert panel. J Hepatol 2003; 38: 364-71.

3. DeLeve LD, Valla DC, Garcia-Tsao G; American Association for the Study Liver Diseases. Vascular disorders of the liver. Hepatology 2009; 49: 1729-64.

4. Shin N, Kim YH, Xu H, Shi HB, Zhang QQ, Colon Pons JP, et al. Redefining Budd-Chiari syndrome: A systematic review. World J Hepatol 2016; 8: 691-702.

5. Darwish Murad S1, Plessier A, Hernandez-Guerra M, Fabris F, Eapen CE, Bahr MJ, et al. Etiology, management, and outcome of the Budd-Chiari syndrome. Ann Intern Med 2009; 151: 167-75.

6. Valla DC. Budd-Chiari syndrome/hepatic venous outflow tract obstruction. Hepatol Int 2018; 12(Suppl 1): 168-80.

7. Qi X, Zhang C, Han G, et al. Prevalence of the JAK2V617F mutation in Chinese patients with Budd-Chiari syndrome and portal vein thrombosis: a prospective study. J Gastroenterol Hepatol 2012; 27: 1036-43.

8. Menon KV, Shah V, Kamath PS. The Budd-Chiari syndrome. N Engl J Med 2004; 350: 578-85.

9. Cazals-Hatem D, Vilgrain V, Genin P, Denninger MH, Durand F, Belghiti J, et al. Arterial and portal circulation and parenchymal changes in Budd- Chiari syndrome: a study in 17 explanted livers. Hepatology 
2003; 37: 510-9.

10. Denninger MH, Chaï Y, Casadevall N, Hillaire S, Guillin MC, Bezeaud A, et al. Cause of portal or hepatic venous thrombosis in adults: the role of multiple concurrent factors. Hepatology 2000; 31: 587-91.

11. Janssen HL, Meinardi JR, Vleggaar FP, van Uum SH, Haagsma EB, van Der Meer FJ, et al. Factor V Leiden mutation, prothrombin gene mutation, and deficiencies in coagulation inhibitors associated with BuddChiari syndrome and portal vein thrombosis: results of a case-control study. Blood 2000; 96: 2364-8.

12. Primignani M, Barosi G, Bergamaschi G, Gianelli U, Fabris F, Reati R, et al. Role of the JAK2 mutation in the diagnosis of chronic myeloproliferative disorders in splanchnic vein thrombosis. Hepatology 2006; 44:1528-34.

13. MacNicholas R, Olliff S, Elias E, Tripathi D. An update on the diagnosis and management of Budd-Chiari syndrome; Expert Rev Gastroenterol Hepatol 2012; 6: 731-44.

14. Parekh J, Matei VM, Canas-Coto A, Friedman D, Lee WM; Acute Liver Failure Study Group. Budd-Chiari syndrome causing acute liver failure: A multicenter case series. Liver Transpl 2017; 23:135-42.

15. Hadengue A, Poliquin M, Vilgrain V, Belghiti J, Degott C, Erlinger S, et al. The changing scene of hepatic vein thrombosis: Recognition of asymptomatic cases. Gastroenterology 1994; 106: 1042-7.

16. Miller WJ, Federle MP, Straub WH, Davis PL. Budd-Chiari syndrome: imaging with pathologic correlation. Abdom Imaging 1993; 18: 329-35.

17. Riggio O, Marzano C, Papa A, Pasquale C, Gasperini ML, Gigante A, et al. Small hepatic veins Budd-Chiari syndrome. J Thromb Thrombolysis 2014 37: 536-9.

18. Valla DC. The diagnosis and management of the Budd-Chiari syndrome: consensus and controversies. Hepatology 2003; 38: 793-803.

19. Seijo S, Plessier A, Hoekstra J, Dell'era A, Mandair D, Rifai K, et al. Good long-term outcome of Budd-Chiari syndrome with a step-wise management. Hepatology 2013; 57:1962-8.

20. de Franchis R, Baveno VI Faculty. Expanding consensus in portal hypertension: Report of the Baveno VI Consensus Workshop: Stratifying risk and individualizing care for portal hypertension. J Hepatol 2015; 63: 743-52.

21. Plessier A, Sibert A, Consigny Y, Hakime A, Zappa M, Denninger MH, et al. Aiming at minimal invasiveness as a therapeutic strategy for BuddChiari syndrome. Hepatology 2006; 44: 1308-16.

22. De Gottardi A, Trebicka J, Klinger C, Plessier A, Seijo S, Terziroli B, et al. Antithrombotic treatment with direct-acting oral anticoagulants in patients with splanchnic vein thrombosis and cirrhosis. Liver Int 2017; 37: 694-9.

23. Fu YF, Li Y, Cui YF, Wei N, Li DC, Xu H. Percutaneous recanalization for combined-type Budd-Chiari syndrome: strategy and long-term outcome. Abdom Imaging 2015; 40: 3240-7.

24. Cui YF, Fu YF, Li DC, Xu H. Percutaneous recanalization for hepatic vein-type Budd-Chiari syndrome: long-term patency and survival. Hepatol Int 2016; 10: 363-9.

25. Tripathi D, Sunderraj L, Vemala V, Mehrzad H, Zia Z, Mangat K, et al. Long-term outcomes following percutaneous hepatic vein recanalization for Budd-Chiari syndrome. Liver Int 2017; 37: 111-20.

26. Zhang F, Wang C, Li Y. The outcomes of interventional treatment for Budd-Chiari syndrome: systematic review and meta-analysis. Abdom Imaging 2015; 40: 601-8.

27. Qi XS, Ren WR, Fan DM, Han GH. Selection of treatment modalities for Budd-Chiari syndrome in China: a preliminary survey of published literature. World J Gastroenterol 2014; 20: 10628-36.

28. Fan X, Liu K, Che Y, Wang S, Wu X, Cao J, Li J. Good clinical outcomes in Budd-Chiari syndrome with hepatic vein occlusion. Dig Dis Sci 2016; 61: 3054-60.

29. Rathod K, Deshmukh H, Shukla A, Popat B, Pandey A, Gupte A, et al. Endovascular treatment of Budd-Chiari syndrome: single center experience. J Gastroenterol Hepatol 2017; 32: 237-43.
30. Shalimar, Kumar A, Kedia S, Sharma H, Gamanagatti SR, Gulati GS, et al. Hepatic venous outflow tract obstruction: treatment outcomes and development of a new prognostic score. Aliment Pharmacol Ther 2016; 43: 1154-67.

31. Han G1, Qi X, Zhang W, He C, Yin Z, Wang J, et al. Percutaneous recanalization for Budd-Chiari syndrome: an 11-year retrospective study on patency and survival in 177 Chinese patients from a single center. Radiology 2013; 266: 657-67.

32. Boyer TD, Haskal ZJ. The role of transjugular intrahepatic portosystemic shunt (TIPS) in the management of portal hypertension: update 2009. Hepatology 2010; 51: 306.

33. LaBerge JM, Ring EJ, Lake JR, Ferrell LD, Doherty MM, Gordon RL, et al. Transjugular intrahepatic portosystemic shunts: preliminary results in 25 patients. J Vasc Surg 1992; 16: 258-67.

34. Peltzer MY, Ring EJ, LaBerge JM, Haskal ZJ, Radosevich PM, Gordon RL. Treatment of Budd-Chiari syndrome with a transjugular intrahepatic portosystemic shunt. J Vasc Interv Radiol 1993; 4: 263-7.

35. Perelló A, García-Pagán JC, Gilabert R, Suárez Y, Moitinho E, Cervantes $\mathrm{F}$, et al. TIPS is a useful long-term derivative therapy for patients with Budd-Chiari syndrome uncontrolled by medical therapy. Hepatology 2002; 35: 132-9.

36. Mancuso A, Fung K, Mela M, Tibballs J, Watkinson A, Burroughs AK, et al. TIPS for acute and chronic Budd-Chiari syndrome: a single-centre experience. J Hepatol 2003; 38: 751-4.

37. Rössle M, Olschewski M, Siegerstetter V, Berger E, Kurz K, Grandt D. The Budd-Chiari syndrome: outcome after treatment with the transjugular intrahepatic portosystemic shunt. Surgery 2004; 135: 394-403.

38. Plessier A, Sibert A, Consigny Y, Hakime A, Zappa M, Denninger MH, et al. Aiming at minimal invasiveness as a therapeutic strategy for BuddChiari syndrome. Hepatology 2006; 44: 1308-16.

39. Mancuso A. Budd-Chiari syndrome management: lights and shadows. World J Hepatol 2011; 3: 262-4.

40. Gandini R, Konda D, Simonetti G. Transjugular intrahepatic portosystemic shunt patency and clinical outcome in patients with Budd-Chiari syndrome: covered versus uncovered stents. Radiology 2006; 241 : 298305.

41. Hernández-Guerra M, López E, Bellot P, Piera C, Turnes J, Abraldes JG, et al. Systemic hemodynamics, vasoactive systems, and plasma volume in patients with severe Budd-Chiari syndrome. Hepatology 2006; 43: 27-33.

42. Garcia-Pagán JC, Heydtmann M, Raffa S, Plessier A, Murad S, Fabris F, et al. TIPS for Budd-Chiari syndrome: long-term results and prognostics factors in 124 patients. Gastroenterology 2008;135: 808-15.

43. Tripathi D, Macnicholas R, Kothari C, Sunderraj L, Al-Hilou H, Rangarajan $\mathrm{B}$, et al. Good clinical outcomes following transjugular intrahepatic portosystemic stent-shunts in Budd-Chiari syndrome. Aliment Pharmacol Ther 2014; 39: 864-72.

44. Hayek G, Ronot M, Plessier A, Sibert A, Abdel-Rehim M, Zappa M, et al. Long-term Outcome and Analysis of Dysfunction of Transjugular Intrahepatic Portosystemic Shunt Placement in Chronic Primary BuddChiari Syndrome. Radiology 2017; 283: 280-92.

45. Shalimar, Gamanagatti SR, Patel AH, Kedia S, Nayak B, Gunjan D, et al. Long-term outcomes of transjugular intrahepatic portosystemic shunt in Indian patients with Budd-Chiari syndrome. Eur J Gastroenterol Hepatol. 2017; 29: 1174-82.

46. Spiliopoulos S, Lalenis C, Konstantos C, Palialiexis K, Tsitskari M, Reppas L, et al. Long-term efficacy of Transjugular Intrahepatic Portosystemic Shunt treatment for Budd-Chiari Syndrome. Hell J Radiol 2017; 2: 12-19.

47. Paladini I, Barbosa F, Compagnoni NM, Militi A, Vercelli R, Migliorisi C, et al. Transjugular intrahepatic portosystemic shunt (TIPS) in the treatment of patients with symptomatic Budd-Chiari syndrome: Patency assessment, overall survival, and long term results. Cardiovasc Intervent Radiol 2017; 40 (Suppl 2): S350-1.

48. Sonavane A, Amarapurkar D. Long term survival of patients undergoing 
TIPS in Budd-Chiari syndrome. J Clin Exp Hepatol 2015; 5: S53-4.

49. Qi X, Guo W, He C, Zhang W, Wu F, Yin Z, et al. Transjugular intrahepatic portosystemic shunt for Budd-Chiari syndrome: techniques, indications and results on 51 Chinese patients from a single centre. Liver Int 2014; 34: 1164-75.

50. MacNaughtan J, Hogan BJ, Tritto G, Burroughs AK. TIPS outcomes for Budd-Chiari: A single tertiary centre experience. Gut 2011; 60(Suppl 2): A8.

51. Qi X, Yang M, Fan D, Han G. Transjugular intrahepatic portosystemic shunt in the treatment of Budd-Chiari syndrome: a critical review of literatures. Scand J Gastroenterol 2013; 48: 771-84.

52. Wu T, Wang L, Xiao Q, Wang B, Li S, Li X, et al. Percutaneous balloon angioplasty of inferior vena cava in Budd-Chiari syndrome-R1. Int J Cardiol 2002; 83: 175-8.

53. Yang XL, Cheng TO, Chen CR. Successful treatment by percutaneous balloon angioplasty of Budd-Chiari syndrome caused by membranous obstruction of inferior vena cava: 8-year follow-up study. J Am Coll Cardiol 1996; 28: 1720-4

54. Zhang CQ1, Fu LN, Xu L, Zhang GQ, Jia T, Liu JY, et al. Long-term effect of stent placement in 115 patients with Budd-Chiari syndrome. World J Gastroenterol 2003; 9: 2587-91.

55. Xu K, Feng B, Zhong H, Zhang X, Su H, Li H, et al. Clinical application of interventional techniques in the treatment of Budd-Chiari syndrome. Chin Med J (Engl) 2003; 116: 609-15.

56. Qiao T, Liu CJ, Liu C, Chen K, Zhang XB, Zu MH. Interventional endovascular treatment for Budd-Chiari syndrome with long-term follow-up. Swiss Med Wkly 2005; 135: 318-26.

57. Qi X, He C, Han G, Yin Z, Wu F, Zhang Q, et al. Prevalence of paroxysmal nocturnal hemoglobinuria in Chinese patients with Budd-Chiari syndrome or portal vein thrombosis. J Gastroenterol Hepatol 2013; 28 : 148-52.
58. Qi Xl, Wu F, Ren W, He C, Yin Z, Niu J, et al. Thrombotic risk factors in Chinese Budd-Chiari syndrome patients. An observational study with a systematic review of the literature. Thromb Haemost 2013; 109: 878-84.

59. Valla DC. Hepatic venous outflow tract obstruction etiopathogenesis: Asia versus the West. J Gastroenterol Hepatol 2004; 19: S204-11.

60. Langlet $P$, Valla $D$. Is surgical portosystemic shunt the treatment of choice in Budd-Chiari syndrome? Acta Gastroenterol Belg 2002; 65: 15560.

61. Panis Y, Belghiti J, Valla D, Benhamou JP, Fékété F. Portosystemic shunt in Budd-Chiari syndrome: Long-term survival and factors affecting shunt patency in 25 patients in Western countries. Surgery 1994; 115: 276-81.

62. Park JS, Federle MP, Sass DA. Education and imaging. Hepatobiliary and pancreatic: Budd-Chiari syndrome presenting as a caudate lobe pseudotumor. J Gastroenterol Hepatol 2010; 25: 219.

63. Ulrich F, Pratschke J, Neumann U, Pascher A, Puhl G, Fellmer P, et al. Eighteen years of liver transplantation experience in patients with advanced Budd-Chiari syndrome. Liver Transpl 2008; 14: 144-50.

64. Mentha G, Giostra E, Majno PE, Bechstein WO, Neuhaus P, O’Grady J, et al. Liver transplantation for Budd-Chiari syndrome: A European study on 248 patients from 51 centres. J Hepatol 2006; 44: 520-8.

65. Segev DL, Nguyen GC, Locke JE, Simpkins CE, Montgomery RA, Maley WR, et al. Twenty years of liver transplantation for Budd-Chiari syndrome: A national registry analysis. Liver Transpl 2007; 13: 1285-94.

66. He F, Zhao H, Dai S, Wu Y, Wang L, Huang H, et al. Transjugular intrahepatic portosystemic shunt for Budd-Chiari syndrome with diffuse occlusion of hepatic veins. Sci Rep 2016; 6: 36380.

How to cite this article: Khan F, Mehrzad H, Tripathi D. Timing of transjugular intrahepatic portosystemic stent-shunt in Budd-Chiari syndrome: A UK hepatologist's perspective. J Transl Intern Med 2018; 6: $97-104$. 